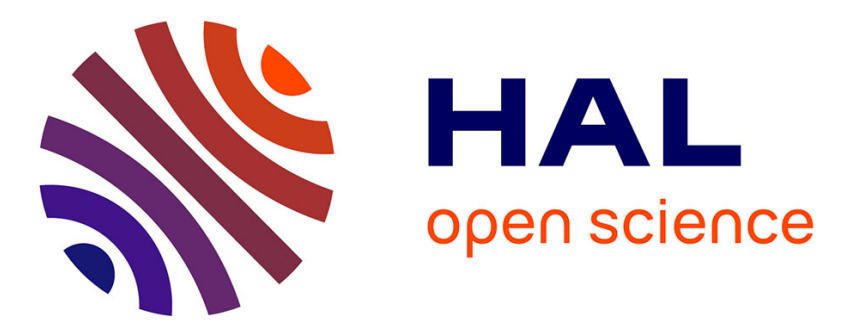

\title{
Ir-Rh thin films as high-temperature electrodes for surface acoustic wave sensor applications
}

Amine Taguett, Thierry Aubert, Marc Lomello, Ouarda Legrani, Omar Elmazria, Jaafar Ghanbaja, Abdelkrim Talbi

\section{- To cite this version:}

Amine Taguett, Thierry Aubert, Marc Lomello, Ouarda Legrani, Omar Elmazria, et al.. Ir-Rh thin films as high-temperature electrodes for surface acoustic wave sensor applications. Sensors and Actuators A: Physical , 2016, 243, pp.35-42. 10.1016/j.sna.2016.03.008 . hal-01288956

\section{HAL Id: hal-01288956 \\ https://hal-centralesupelec.archives-ouvertes.fr/hal-01288956}

Submitted on 25 Mar 2021

HAL is a multi-disciplinary open access archive for the deposit and dissemination of scientific research documents, whether they are published or not. The documents may come from teaching and research institutions in France or abroad, or from public or private research centers.
L'archive ouverte pluridisciplinaire HAL, est destinée au dépôt et à la diffusion de documents scientifiques de niveau recherche, publiés ou non, émanant des établissements d'enseignement et de recherche français ou étrangers, des laboratoires publics ou privés. 


\section{Ir-Rh thin films as high-temperature electrodes}

\section{for surface acoustic wave sensor applications}

Amine Taguett ${ }^{1}$, Thierry Aubert ${ }^{1,2}$, Marc Lomello ${ }^{1}$, Ouarda Legrani ${ }^{2}$, Omar Elmazria $^{3}$, Jaafar Ghanbaja $^{3}$, Abdelkrim Talbi ${ }^{4}$

\footnotetext{
${ }^{1}$ Laboratoire SYMME, Université Savoie Mont Blanc, 74944 Annecy-le-Vieux, France

${ }^{2}$ Laboratoire Matériaux Optiques, Photonique et Systèmes (LMOPS), CentraleSupélec-Université de Lorraine, 57070 Metz, France

${ }^{3}$ Institut Jean Lamour (IJL), UMR 7198 Université de Lorraine-CNRS, 54506 Vandoeuvre-lès-Nancy, France

${ }^{4}$ LIA LEMAC/LICS - IEMN, UMR 8520, EC Lille-CNRS, 59652 Villeneuve d'Ascq, France.
}

Abstract-The achievement of surface acoustic wave (SAW) devices stable in hightemperature oxidizing atmospheres requires the development of conductive thin film electrodes that can withstand such harsh conditions. Recent studies have demonstrated the suitability of Pt-based alloys, multilayers or nanocomposite films for temperatures up to $8^{\circ}{ }^{\circ}$ C. Electrodes based on new materials and structures still have to be developed for applications taking place at higher temperatures. In this perspective, thin films based on iridium could be good candidates regarding the high melting point, and thus the low diffusion coefficients of this noble metal. In particular, Ir-Rh bulk alloys have shown superior performance as spark plug electrodes, which have to resist concurrently to physical and chemical wear such as high-temperature SAW electrodes. Consequently, this paper deals with the high-temperature behavior of Ir-Rh thin films. Ir-Rh alloys and multilayers films, with an Ir atomic ratio between 10 and $50 \%$, are deposited by one-gun 
electron beam evaporation method. The impact on the films of a 4-days annealing treatment at $800^{\circ} \mathrm{C}$ in air is studied by $\mathrm{X}$-ray diffraction, scanning and transmission electron microscopy, electron energy loss spectroscopy and four-points probe resistivity measurements. It turns out that all the films oxidized during the annealing period. The post-annealing electrical properties are highly dependent of the initial composition of the film: the higher is the Ir rate in the film, the lower is the electrical resistivity after annealing. Moreover, an $\mathrm{Rh}_{2} \mathrm{O}_{3}$ overlayer, with a thickness of some tens of nanometers, forms at the surface of the film, confirming previous observations made on Ir-Rh bulk alloys. First SAW measurements made on devices based on $\operatorname{Ir}_{30} R_{h_{70}}$ alloy electrodes are very promising as a SAW signal is still clearly visible after the 4-days annealing process, while no agglomeration phenomenon can be observed.

Index Terms — high-temperature; SAW; Ir-Rh electrodes; multilayers film

\section{INTRODUCTION}

There is currently a strong industrial request to develop wireless measurement solutions for a variety of industrial applications taking place between $200^{\circ} \mathrm{C}$ and $1000^{\circ} \mathrm{C}$ that cannot be addressed by wired sensors. For instance, in metallurgy domain, such sensor could allow an accurate monitoring of the temperature at different positions on a steel band undergoing a thermal annealing treatment cycle, and thus a better adjustment of the annealing line parameters. Surface acoustic wave (SAW) technology could meet this need as SAW devices are passive components, thus requiring neither embedded electronics nor power source to be wirelessly interrogated. These devices are composed of a piezoelectric substrate on which are built interdigited 
conductive electrodes called interdigital transducers (IDTs). The typical thickness of the thin film from which the IDTs are lithographed is one hundred nanometers. One of the main challenges to face in order to achieve high-temperature wireless SAW sensors is the development of the constitutive materials able to withstand elevated temperatures up to $1000^{\circ} \mathrm{C}$ and corrosive atmospheres, starting with hot air. Concerning the piezoelectric substrate, langasite $\left(\mathrm{La}_{3} \mathrm{Ga}_{5} \mathrm{SiO}_{14}\right.$; LGS) is currently the most appropriate candidate. It has been intensively studied, demonstrating a good stability at high temperature $[1,2]$. However, it has to be noted that, under high-temperature vacuum conditions, LGS suffers from surface degradation related to gallium and oxygen losses [3-5]. Regarding the IDTs, the use of a material having good corrosion resistance seems required. First studies naturally turned to platinum regarding its exceptional noble character and a melting temperature as high as $1773^{\circ} \mathrm{C}[6,7]$. However, it was observed that $100 \mathrm{~nm}$-thick Pt thin films agglomerate at temperatures higher than $700^{\circ} \mathrm{C}$ [8-10]. Agglomeration is a phenomenon specific to thin films, related to their large surface tension, which transforms a continuous thin film in a more stable configuration from the thermodynamics point of view, namely in a collection of separate beads. Agglomeration kinetics depends both on the film thickness and the nature of the film material. The thicker is the film, the slower are agglomeration phenomena. On the other side, as agglomeration is driven by atomic diffusion phenomena, it is slower for metals with higher melting temperature and thus smaller diffusion coefficients. Consequently, agglomeration phenomena can be hindered by adding impurities in pure metal films in order to decrease diffusion coefficients. This strategy was successfully employed by Pereira da Cunha et al. who significantly increased the performance of Pt-based IDTs by the use of Pt-Rh alloys, $\mathrm{Pt}-\mathrm{Rh} / \mathrm{ZrO}{ }_{2}$ multilayers and $\mathrm{Pt}-\mathrm{Rh} / \mathrm{ZrO}_{2}$ nanocomposites. This group successfully operated an LGS-based SAW device with $\mathrm{Pt}-10 \% \mathrm{Rh} / \mathrm{ZrO} 2$ nanocomposites electrodes for more than 5 months at $800^{\circ} \mathrm{C}$ in air atmosphere [11]. Since then, new electrode materials and structures have been investigated 
by this group towards establishing stable operation of LGS-based SAW high-temperature sensors at $900^{\circ} \mathrm{C}$ and beyond [12].

In order to achieve electrodes that are able to operate in corrosive atmospheres at temperatures of $800^{\circ} \mathrm{C}$ and more, it could be relevant to replace platinum by a noble metal with lower intrinsic diffusion coefficients. In this context, iridium is an appropriate candidate as its melting temperature $\left(2447^{\circ} \mathrm{C}\right)$ is significantly higher than that of platinum. First investigations on pure Ir electrodes were very promising, confirming the high resistance of iridium thin films to agglomeration phenomena $[10,13]$. However, these results were obtained under vacuum conditions as Ir transforms into volatile $\mathrm{IrO}_{3}$ above $800^{\circ} \mathrm{C}$ in oxidizing environments [14]. This drawback could be overcome by alloying iridium with another element. Indeed, Osamura et al. studied the high-temperature behavior of spark plug electrodes made of various Ir-based alloys, including Ir-W, Ir-Re, Ir-Mo, Ir-Ru, Ir-Hf, Ir-Pt, Ir-Pd, Ir-Ni and Ir-Rh [15]. Material challenges to face for this application are very similar to those encountered in the development of hightemperature SAW IDTs. Indeed, it is necessary to employ a conductive material with a high melting point to improve the sparking wear resistance. Moreover, as spark plugs are exposed to a hot environment (temperature can exceed $2000^{\circ} \mathrm{C}$ ) containing large amounts of oxygen, it is important that the material from which spark plug electrodes are made be highly resistant to oxidation.

Osamura et al. found that among all the investigated Ir-based alloys, Ir-Rh alloys show the best performance in such conditions. In particular, Ir-Rh alloys show a far better resistance to oxidation than pure iridium above $800^{\circ} \mathrm{C}$. This phenomenon was explained by the formation of a thin rhodium oxide passivation layer at the surface of the samples during annealing. In fact, Osamura et al. assumed that Ir atoms close to the surface transform into $\mathrm{IrO}_{3}$ and fly off, so that 
only $\mathrm{Rh}$ atoms remain close to the surface. The latter also oxidize into $\mathrm{Rh}_{2} \mathrm{O}_{3}$ which is a stable oxide that hinders $\mathrm{O}$ diffusion deeper inside the sample. Unfortunately, the thickness of the $\mathrm{Rh}_{2} \mathrm{O}_{3}$ passivation layer is not given in this study. Note that the $\mathrm{Rh}$ protection effect is maximized as soon as the Rh content reaches $10 \mathrm{wt} \%$. Very few other studies were dedicated to Ir-Rh alloys and none of them to Ir-Rh thin films with a thickness in the range of some hundreds nanometers.

Based on Osamura's study, it appears that Ir-Rh thin films could be good candidates for SAW applications taking place in high-temperature oxidizing atmospheres. Consequently, the goal of this study is to make a first investigation on the high-temperature behavior of such Ir-Rh thin films, to determine their relevance for the targeted application.

\section{EXPERIMENTAL}

Ir-Rh thin films were deposited on $\mathrm{Y}$ and $\mathrm{Y}+50^{\circ}$-cut LGS substrates (Witcore Co. Ltd., Jinan, China) by one-gun electron-beam evaporation method (Edwards Auto 306). The base pressure was $3 \cdot 10^{-8}$ mbar. From $\operatorname{Ir}_{70} \mathrm{Rh}_{30}$ alloy pellets, 150 to $300 \mathrm{~nm}$-thick Ir-Rh alloy thin films were deposited without and over a $10 \mathrm{~nm}$-thick $\mathrm{Cr}$ adhesion layer (on Y-cut LGS substrates). From pure Rh and Ir pellets, 120 nm-thick multilayers films (6 to 24 layers) were deposited without adhesion layer (on $\mathrm{Y}+50^{\circ}$-cut LGS substrates).

SAW delay lines operating at $97 \mathrm{MHz}$ were achieved using photolithography process and ion beam etching, from the Ir-Rh alloy thin films with $\mathrm{Cr}$ adhesion layer. The SAW direction was Y-X. The spatial period of the IDTs was $24 \mu \mathrm{m}$.

Unprocessed thin films and SAW devices were annealed in air for 4 days at $800^{\circ} \mathrm{C}$. After annealing, the samples were cooled down to room temperature. As-deposited and annealed samples were investigated by various methods. The morphology was observed by scanning 
electron microscopy (SEM - Zeiss SupraTM 55VP). Phase composition and microstructures were obtained by X-ray diffraction (XRD) in Bragg-Brentano geometry (Bruker D8 advance - CuK $\mathrm{K}_{\alpha 1:} \lambda$ $=1.54056 \AA$ A) and transmission electronic microscopy (TEM - JEOL ARM 200F). TEM lamellas were prepared using focused ion beam (FIB) etching. The chemical composition was determined by scanning transmission electron microscopy-electron energy loss spectroscopy (STEM-EELS). The resistivity of as-deposited and annealed films was measured by the four-points probe method. SAW devices were electrically characterized at room temperature, before and after annealing, using a network analyzer (PNA 5230a, Agilent Technologies Inc., Santa Clara, CA) and an RF prober station (S-1160, Signatone Corp., Gilroy, CA).

\section{RESULTS AND DISCUSSION}

\section{A. Preliminary study: Ir-Rh alloy film deposition}

As mentioned in the introduction section, Osamura's study revealed that Ir-Rh bulk alloys resistance to oxidation is maximized from a rhodium weight concentration of $10 \%$ [15]. However, the behavior of Ir-Rh thin films regarding oxidation is unknown. Consequently, in order to secure the $\mathrm{Rh}$ protective effect, first evaporations were made from Ir-Rh pellets containing 19 wt.\% (30 at.\%) of rhodium. Fig. 1 shows the TEM cross-section image of a 300 nm-thick deposited film. 


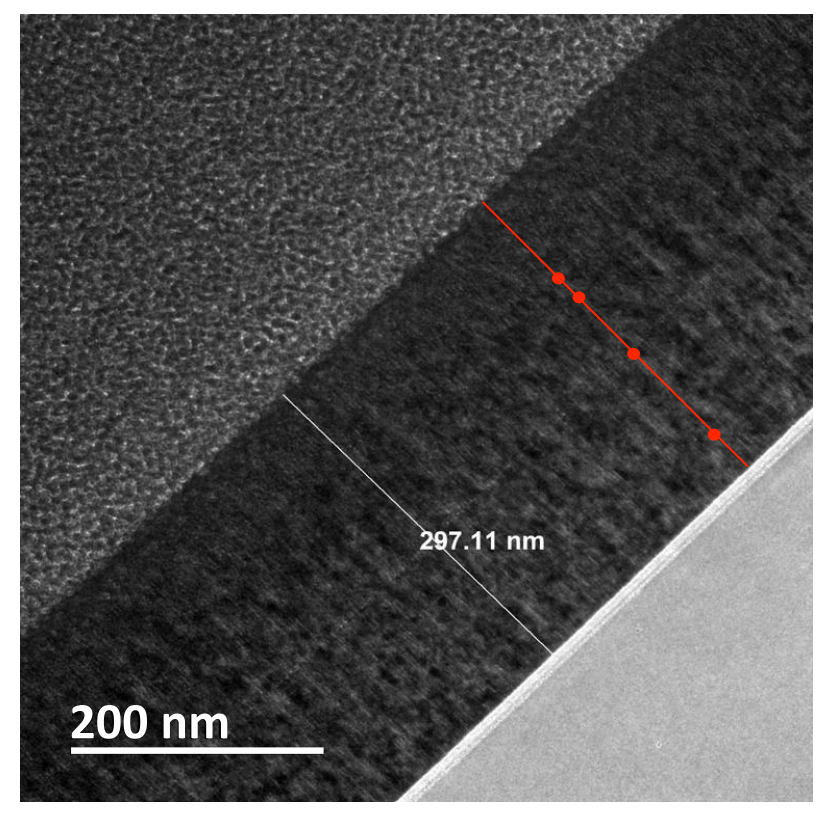

Figure 1: Cross-section bright-field TEM image of an as-deposited $300 \mathrm{~nm}$-thick $\operatorname{Ir}_{10} \mathrm{Rh}_{90}$ thin film.

Red points indicate the EELS measurements locations.

EELS measurements were performed at different locations of this film (Tab. I). It appears that the overall composition of the film is far from being $\operatorname{Ir}_{70} \mathrm{Rh}_{30}$, but rather $\operatorname{Ir}_{10} \mathrm{Rh}_{90}$. The first 100 nanometers (which is the typical IDT thickness) even contain less than 3 at.\% of iridium. Based on the physical properties of rhodium and iridium, namely the melting temperatures $\left(1963^{\circ} \mathrm{C}\right.$ and $2447^{\circ} \mathrm{C}$, respectively) and the enthalpies of vaporization $\left(493 \mathrm{~kJ} \cdot \mathrm{mol}^{-1}\right.$ and $604 \mathrm{~kJ} \cdot \mathrm{mol}^{-1}$, respectively), it can be assumed that this phenomenon comes from the fact that the evaporation rate of rhodium is significantly larger than the one of iridium. Consequently, the Ir rate in the e-beam target and thus in the deposited film progressively increases all along the deposition process, as can be seen in Tab. I. This drawback was advantageously employed in the present study to deposit films with different compositions from the $\operatorname{Ir}_{70} \mathrm{Rh}_{30}$ alloy pellets. In the following, results obtained with $\operatorname{Ir}_{10} \mathrm{Rh}_{90}$ and $\mathrm{Ir}_{30} \mathrm{Rh}_{70}$ alloy films will be shown. 
The deposited alloy films showed very poor adhesion properties on bare LGS substrates. As the first deposited layers are nearly Rh layers, this means that rhodium element has not enough affinity for oxygen to form firm bonds with an oxide substrate, such as LGS. Thereafter, a 10nm-thick chromium adhesion layer was successfully employed to enhance the adhesion quality between the Ir-Rh alloys films and the LGS substrates.

Table I: Ir \& Rh relative rates in Ir-Rh alloy films as given by EELS measurements.

Measurement locations are shown on Fig. 1

\begin{tabular}{|c|c|c|c|c|}
\hline $\begin{array}{c}\text { Measurement } \\
\text { location number }\end{array}$ & 1 & 2 & 3 & 4 \\
\hline Rh (at.\%) & 98 & 96 & 91 & 89 \\
\hline Ir (at.\%) & 2 & 4 & 9 & 11 \\
\hline
\end{tabular}

\section{B. Ir-Rh multilayers film deposition}

As described hereinabove, the control of the stoichiometry of Ir-Rh alloy thin films deposited by one-gun electron-beam evaporation is very tricky. Consequently, the rest of the study was dedicated to multilayers films composed by Ir and $\mathrm{Rh}$ nanolayers alternately evaporated from pure Ir and $\mathrm{Rh}$ pellets respectively. Thereby, the overall film composition depends on the thickness ratio between the successive Ir and $\mathrm{Rh}$ nanolayers.

Let us call $n$ the number of moles in one nanolayer, $m$ the mass of the nanolayer, $M$ the molar mass of the element constituting the nanolayer, $\rho$ the density of the nanolayer, $S$ the surface of the substrate and $t$ the thickness of the nanolayer. Thus, $n$ can be expressed as:

$$
n=\frac{m}{M}=\frac{\rho t S}{M}
$$


Finally, the atomic ratio between rhodium and iridium elements in the multilayers film is:

$$
\frac{n_{R h}}{n_{I r}}=\frac{\rho_{R h}}{\rho_{I r}} \frac{M_{I r}}{M_{R h}} \frac{t_{R h}}{t_{I r}}=1.027 \frac{t_{R h}}{t_{I r}}
$$

Thereafter, the targeted atomic ratio was 1 (in order to obtain $\operatorname{Ir}_{50} \mathrm{Rh}_{50}$ multilayers films), so Ir and Rh nanolayers of same thickness were successively deposited. As Sakharov et al. reported that Ir thin films adhere well to LGS substrates [16], all multilayers films were successfully deposited starting by an Ir nanolayer. In the same way, the films were ended by an Rh nanolayer in order to take advantage of the $\mathrm{Rh}_{2} \mathrm{O}_{3}$ passivating layer that could form at the surface. The total thickness of the deposited films was $120 \mathrm{~nm}$. Three kinds of film nanostructure were investigated, depending on the number of nanolayers successively deposited (Tab II). Fig.2 shows the TEM cross-section image of an as-deposited 12x10 nm multilayer film.

Table II: Description of the three investigated nanostructures.

\begin{tabular}{|c|c|c|c|}
\hline Sample number & 1 & 2 & 3 \\
\hline $\begin{array}{c}\text { Number of } \\
\text { deposited } \\
\text { nanolayers }\end{array}$ & 6 & 12 & 24 \\
\hline $\begin{array}{c}\text { Nanolayer } \\
\text { thickness (nm) }\end{array}$ & 20 & 10 & 5 \\
\hline
\end{tabular}




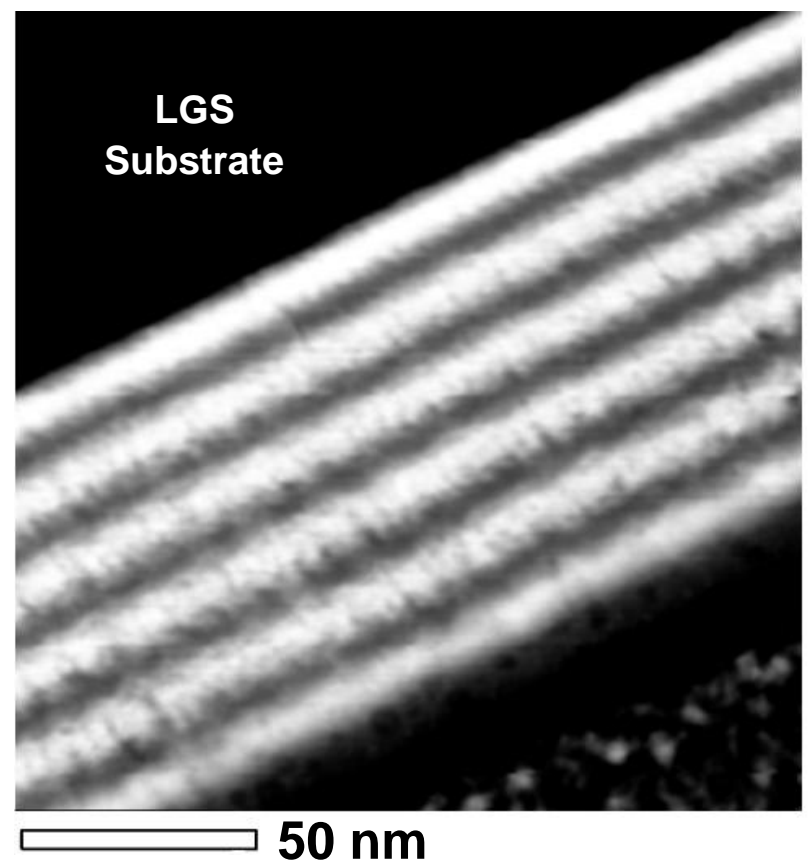

Figure 2: Cross-section bright-field TEM image of an as-deposited $12 \times 10 \mathrm{~nm} \mathrm{Ir}{ }_{50} \operatorname{Rh}_{50}$ multilayers thin film.

\section{High-temperature behavior}

Fig. 3 shows the XRD patterns of the $\operatorname{Ir}_{10} R h_{90}, \operatorname{Ir}_{30} R h_{70}$ alloy and $\operatorname{Ir}_{50} \mathrm{Rh}_{50}$ multilayers films before and after a 4-days annealing period at $800^{\circ} \mathrm{C}$. Based on the calculated $\mathrm{Ir}-\mathrm{Rh}$ phase diagram available in the literature [17], in which no intermetallic compound can be found, we assume that the alloy films are solid-solution-type. All kinds of as-deposited films crystallized in the face centered cubic (fcc) phase, being textured in the [111] direction.

$\mathrm{Ir}_{\mathrm{x}} \mathrm{Rh}_{1-\mathrm{x}}$ (111) XRD peaks are not visible anymore on the XRD patterns of annealed samples. They are substituted by peaks related to several oxides phases. Some peaks can surely be identified as orthorhombic $\mathrm{Rh}_{2} \mathrm{O}_{3}$ (noted as o- $\mathrm{Rh}_{2} \mathrm{O}_{3}$ in Fig.3a) in the case of alloy films and as rhombohedral $\mathrm{Rh}_{2} \mathrm{O}_{3}$ (noted as $\mathrm{rh}-\mathrm{Rh}_{2} \mathrm{O}_{3}$ in Fig.3b) in the case of multilayer films. 


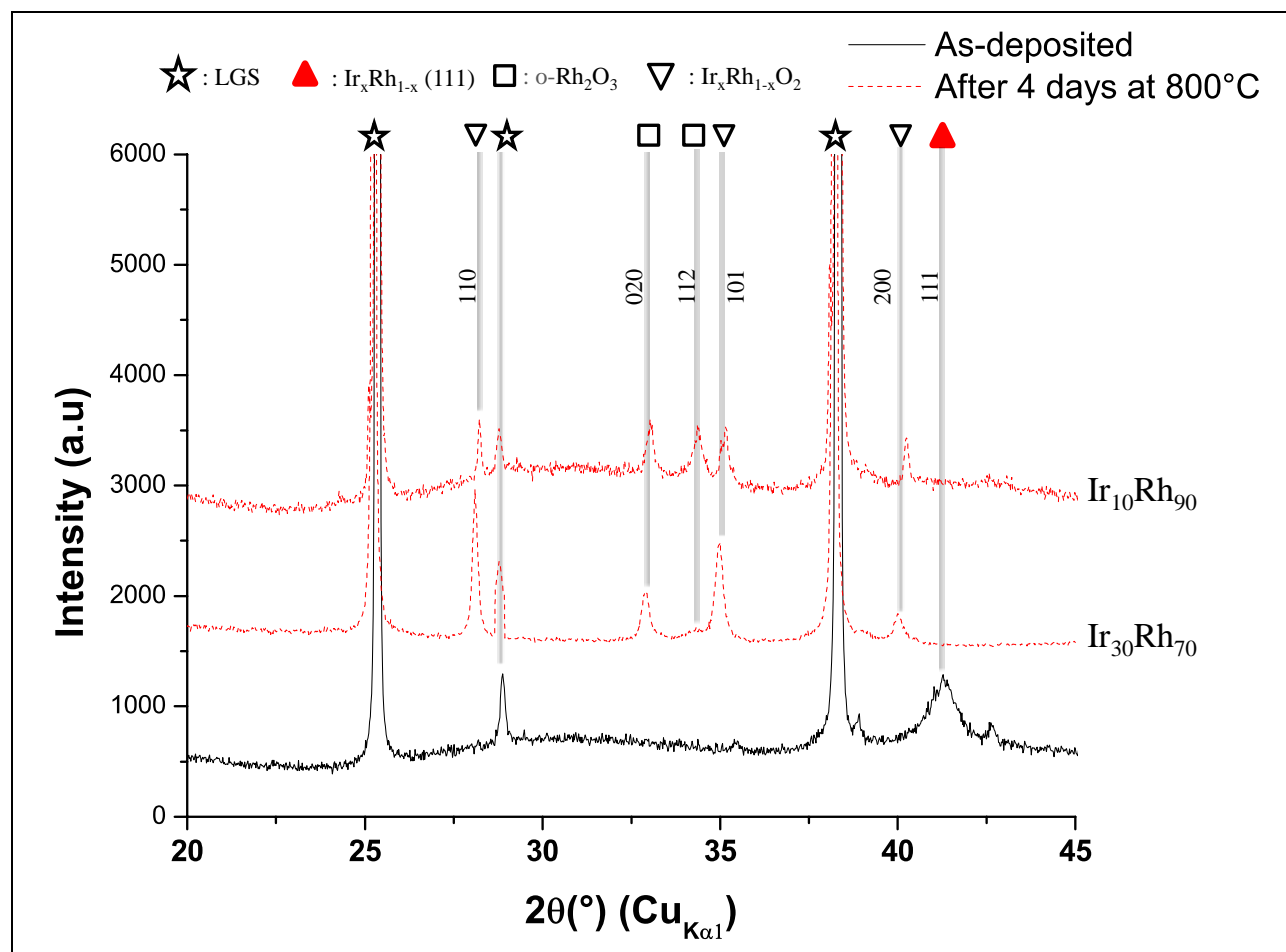

(a)

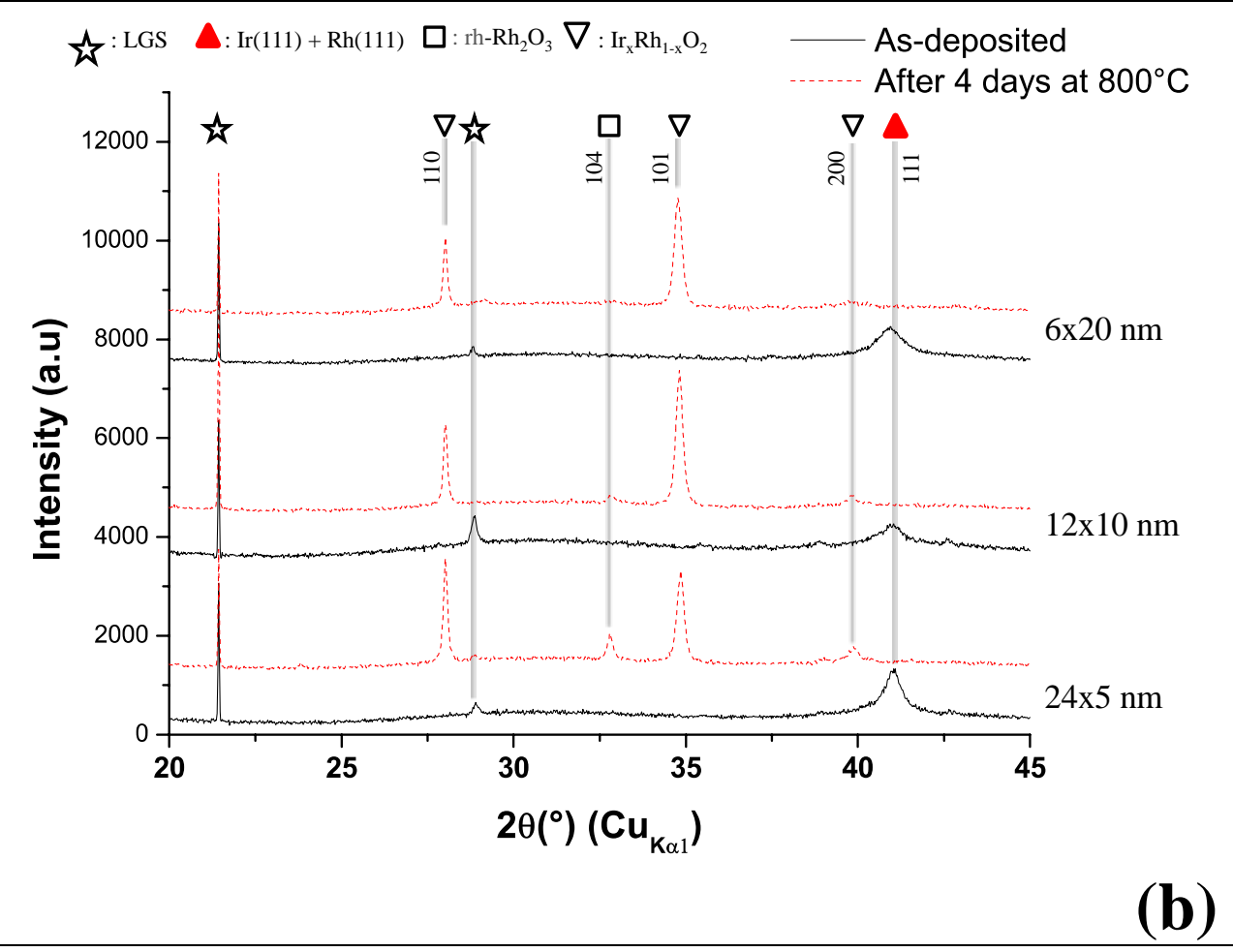

Figure 3: As-deposited and post-annealing XRD patterns

of $\operatorname{Ir}_{10} R h_{90}$ alloy film, $\operatorname{Ir}_{30} R h_{70}$ alloy film (a) and $\operatorname{Ir}_{50} R h_{50}$ multilayers films (b). 
This difference is unexplained. The remaining peaks could be attributed either to $\mathrm{IrO}_{2}$ or $\mathrm{RhO}_{2}$ which are both tetragonal form. The theoretical peaks of these two phases are very close and none of them coincides exactly with the experimental reflexes. By adjusting the lattice parameters of $\mathrm{IrO}_{2}$ (or $\mathrm{RhO}_{2}$ which comes to the same thing), a good match was obtained. Consequently, we assume that the actual tetragonal phase is $\mathrm{Ir}_{\mathrm{x}} \mathrm{Rh}_{1-\mathrm{x}} \mathrm{O}_{2}$ rather than $\mathrm{IrO}_{2}$ or $\mathrm{RhO}_{2}$. This assumption is strengthened by the fact that the lattice parameters of the hypothetical $\operatorname{Ir}_{\mathrm{x}} \mathrm{Rh}_{1-\mathrm{x}} \mathrm{O}_{2}$ phase were found to follow well the Vegard law.

The resistivity of the as-deposited $\operatorname{Ir}_{10} R h_{90}$ and $\operatorname{Ir}_{30} R h_{70}$ alloy films is one order of magnitude higher than conventional values for metallic thin films (Tab. III). On the other hand, the electrical resistivity of the as-deposited multilayers films is comprised between $25 \mu \Omega \cdot \mathrm{cm}$ for the $24 \times 5 \mathrm{~nm}$ sample and $40 \mu \Omega \cdot \mathrm{cm}$ for the $6 \times 20 \mathrm{~nm}$ one.

The effect of the annealing process on the electrical properties of the different films is highly dependent of their composition. In the case of the $\mathrm{Ir}_{10} \mathrm{Rh}_{90}$ alloy films, the electrical resistivity gained two orders of magnitude, reaching the value of $21000 \mu \Omega \cdot \mathrm{cm}$. The $\operatorname{Ir}_{30} \mathrm{Rh}_{70}$ alloy films showed a much smaller rise, as the post-annealing resistivity is equal to $400 \mu \Omega \cdot \mathrm{cm}$. Regarding the $\operatorname{Ir}_{50} \mathrm{Rh}_{50}$ multilayers films the final resistivity is lower than $200 \mu \Omega \cdot \mathrm{cm}$, independently from the film nanostructure.

The decrease of the resistivity with the Ir rate can be explained by the large difference in the electrical proprieties between rhodium oxides and $\mathrm{IrO}_{2}$. Indeed, Hämäläinen et al. reported an electrical resistivity between 5000 and $11000 \mu \Omega \cdot \mathrm{cm}$ for films mixing $\mathrm{RhO}_{2}$ and $\mathrm{Rh}_{2} \mathrm{O}_{3}$ grains [18]. On the other hand, $\mathrm{IrO}_{2}$ shows an exceptionally low resistivity for an oxide. El Kahkani et al. found a bulk value equal to $42 \mu \Omega \cdot \mathrm{cm}$ [19], while values between 47 and $300 \mu \Omega \cdot \mathrm{cm}$ were measured for $\mathrm{IrO}_{2}$ thin films $[20,21]$. Consequently, we assume that the conductivity of the $\mathrm{Ir}_{\mathrm{x}} \mathrm{Rh}_{1-\mathrm{x}} \mathrm{O}_{2}$ phase increases with the stoichiometric coefficient $\mathrm{x}$. Moreover, one can observe in 
Fig. 3 that the relative intensity of $\mathrm{Rh}_{2} \mathrm{O}_{3}$ reflexes (compared to the intensity of $\mathrm{Ir}_{\mathrm{x}} \mathrm{Rh}_{1-\mathrm{x}} \mathrm{O}_{2}$ peaks) significantly decreases when $\mathrm{Rh}$ atomic content goes from $90 \%$ to $70 \%$, and then from $70 \%$ to $50 \%$. This phenomenon could indicate that the relative quantity of $\mathrm{Rh}_{2} \mathrm{O}_{3}$ (compared to the quantity of $\operatorname{Ir}_{x} \mathrm{Rh}_{1-\mathrm{x}} \mathrm{O}_{2}$ ) in the post-annealed films decreases when the initial Ir content increases. These two factors, i.e. increase of $\operatorname{Ir}_{\mathrm{x}} \mathrm{Rh}_{1-\mathrm{x}} \mathrm{O}_{2}$ conductivity and decrease of the relative quantity of $\mathrm{Rh}_{2} \mathrm{O}_{3}$, could contribute to the increase of the conductivity of the post-annealed films with the initial Ir content.

Table III: Specific electrical resistance (in $\mu \Omega \cdot \mathrm{cm}$ ) of the different samples before and after annealing.

\begin{tabular}{|c|c|c|c|c|c|}
\cline { 2 - 5 } \multicolumn{1}{c|}{} & $\begin{array}{c}\mathrm{Ir}_{10} \mathrm{Rh}_{90} \\
\text { alloy film }\end{array}$ & $\begin{array}{c}\mathrm{Ir}_{30} \mathrm{Rh}_{70} \\
\text { alloy film }\end{array}$ & $\begin{array}{c}\mathrm{Ir}_{50} \mathrm{Rh}_{50} \\
\text { multilayer film } \\
(6 \times 20 \mathrm{~nm})\end{array}$ & $\begin{array}{c}\mathrm{Ir}_{50} \mathrm{Rh}_{50} \\
\text { multilayer film } \\
(12 \times 10 \mathrm{~nm})\end{array}$ & $\begin{array}{c}\mathrm{Ir}_{50} \mathrm{Rh}_{50} \\
\text { multilayer film } \\
(24 \times 5 \mathrm{~nm})\end{array}$ \\
\hline As-deposited & 125 & 116 & 39.6 & 34.6 & 25.5 \\
\hline $\begin{array}{c}\text { After } \\
100 \text { hours } \\
\text { @ 800 }\end{array}$ & $2.1 \cdot 10^{\circ}$ & 400 & 189 & 188 & 186 \\
\hline
\end{tabular}

The influence of the annealing process on the nanostructure of the multilayers films was examined by TEM analyses (Fig. 4). It can be observed that the multilayered structure was lost during annealing while a surface layer formed. The latter is completely Ir-depleted as evidenced by the STEM-EELS maping (Fig. 5). Quantitative EELS measurements reveal the $\mathrm{Rh}_{2} \mathrm{O}_{3}$ nature of this layer (Tab. IV). In other words, this result fully confirms Osamura's observations on Ir-Rh bulk alloys: an $\mathrm{Rh}_{2} \mathrm{O}_{3}$ mantle forms at the surface of the films during annealing [15].

The thickness of the $\mathrm{Rh}_{2} \mathrm{O}_{3}$ surface layer depends on the initial nanostructure of the multilayers films: about $30 \mathrm{~nm}$ for the $24 \times 5 \mathrm{~nm}$ sample (Fig. 4a) while it is close to $50 \mathrm{~nm}$ for the $12 \times 10 \mathrm{~nm}$ one (Fig. 4b). The inner part of the film is $\mathrm{Rh}$-depleted, which means that $\mathrm{Rh}$ atoms diffuse towards the surface layer during annealing (Tab. IV). 


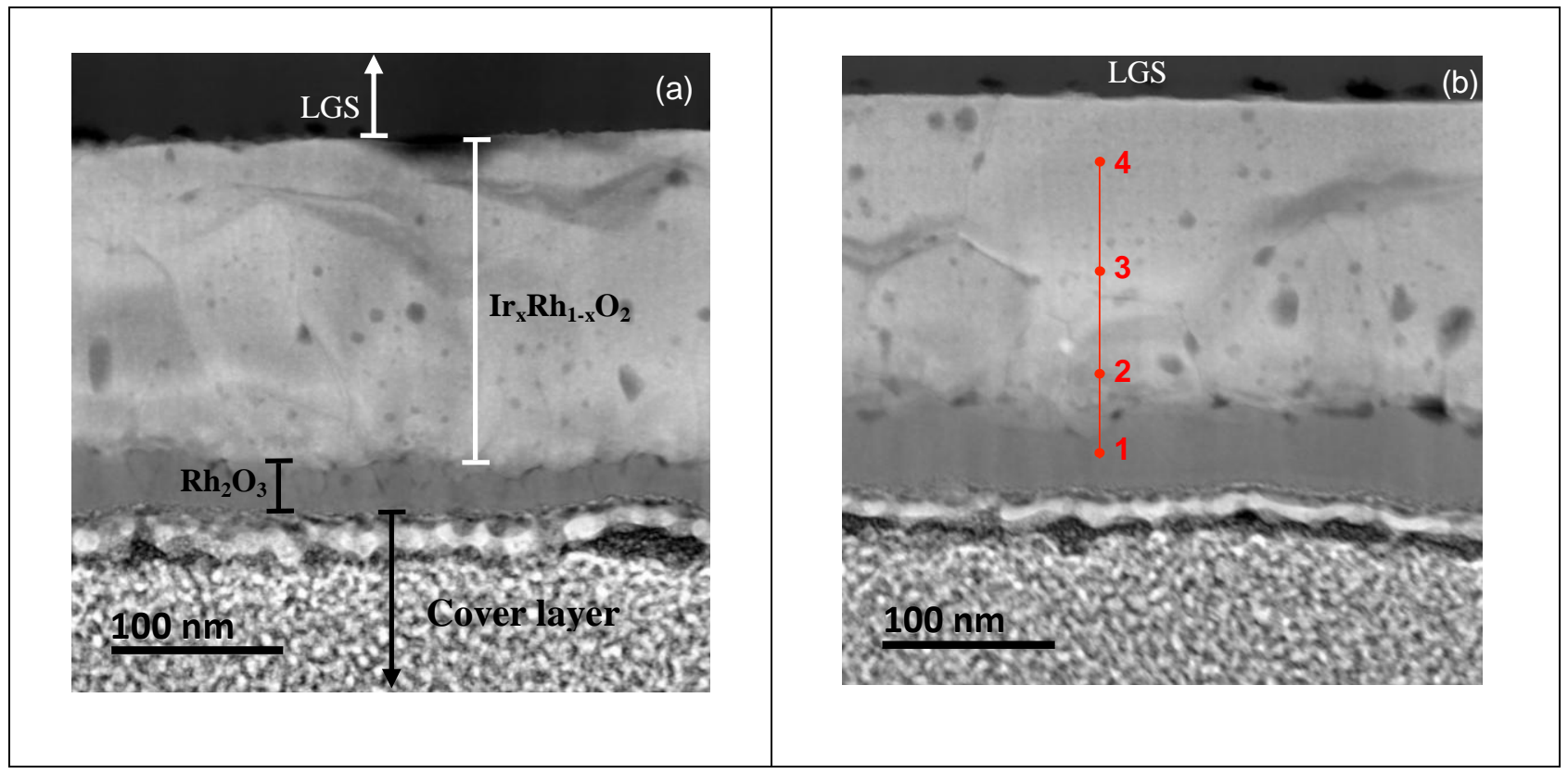

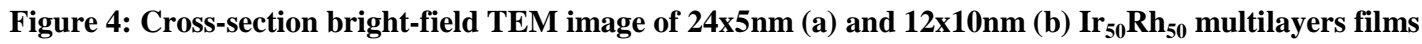
after 100 hours of annealing at $800^{\circ} \mathrm{C}$ in air.

Red points indicate the EELS measurements locations.

Figure 5: STEM-EELS mapping of the 12x10nm multilayered films after 100 hours of annealing at $800^{\circ} \mathrm{C}$ in air: $\operatorname{Ir}$ (orange), $\mathrm{Rh}$ (green) and $\mathrm{O}$ (blue).

Table IV: EELS relative chemical composition of the $12 \times 10 \mathrm{~nm}$ multilayered films after 100 hours of annealing at $800^{\circ} \mathrm{C}$.

Measurement locations are shown on Fig. 4b

\begin{tabular}{|c|c|c|c|c|}
\hline $\begin{array}{c}\text { Measurement } \\
\text { location number }\end{array}$ & 1 & 2 & 3 & 4 \\
\hline Rh (at.\%) & 39.9 & 20.7 & 8.0 & 14.6 \\
\hline Ir (at.\%) & 0.3 & 17.2 & 26.5 & 23.6 \\
\hline O (at.\%) & 59.8 & 62.1 & 65.5 & 61.8 \\
\hline
\end{tabular}

First SAW measurements were realized on devices based on $150 \mathrm{~nm}$-thick $\operatorname{Ir}_{10} \mathrm{Rh}_{90}$ alloy films with $\mathrm{Cr}$ adhesion layer, before and after a 4-days annealing period at $800^{\circ} \mathrm{C}$. As a reminder, the 
IDTs are fully oxidized after this annealing process, their resistivity reaching $21000 \mu \Omega \cdot \mathrm{cm}$, as described in the previous section. For that no signal has been registered after annealing. On the contrary, the SAW measurements performed on devices based on $150 \mathrm{~nm}$-thick $\mathrm{Ir}_{30} \mathrm{Rh}_{70}$ alloy films show that a SAW signal is still clearly visible after annealing (Fig. 6). Insertion losses increased by $8 \mathrm{~dB}$ during heating, which is certainly related to the threefold increase of the film electrical resistivity (Tab. III). In the same time, the operating frequency shifted towards lower values. The origin of this phenomenon could be mass loading effect, since the mass of the IDTs increased during oxidation process. No agglomeration phenomena can be observed on the IDTs after the 4-days annealing period (Fig. 7). However, some blisters are visible and the finger edges are peeling off. These phenomena could indicate the unsuitability of the $\mathrm{Cr}$ adhesion layer for high-temperature applications.

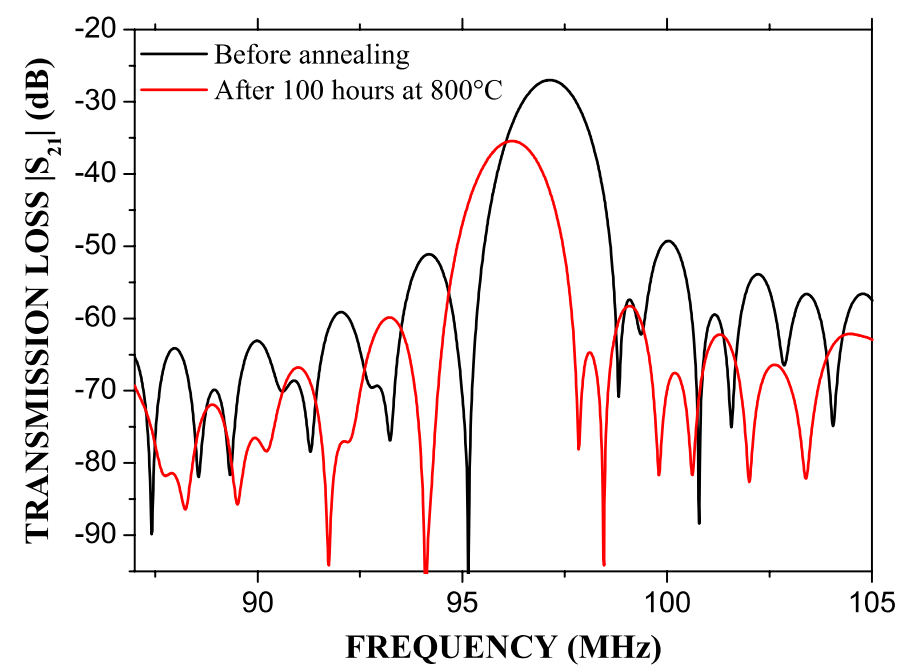

Figure 6: Frequency response $\left(S_{21}\right.$ magnitude) of a SAW device based on LGS substrate and $150 \mathrm{~nm}$-thick $\operatorname{Ir}_{30} \mathrm{Rh}_{70}$ alloy thin film before and after a 4-days annealing period at $800^{\circ} \mathrm{C}$ in air. 


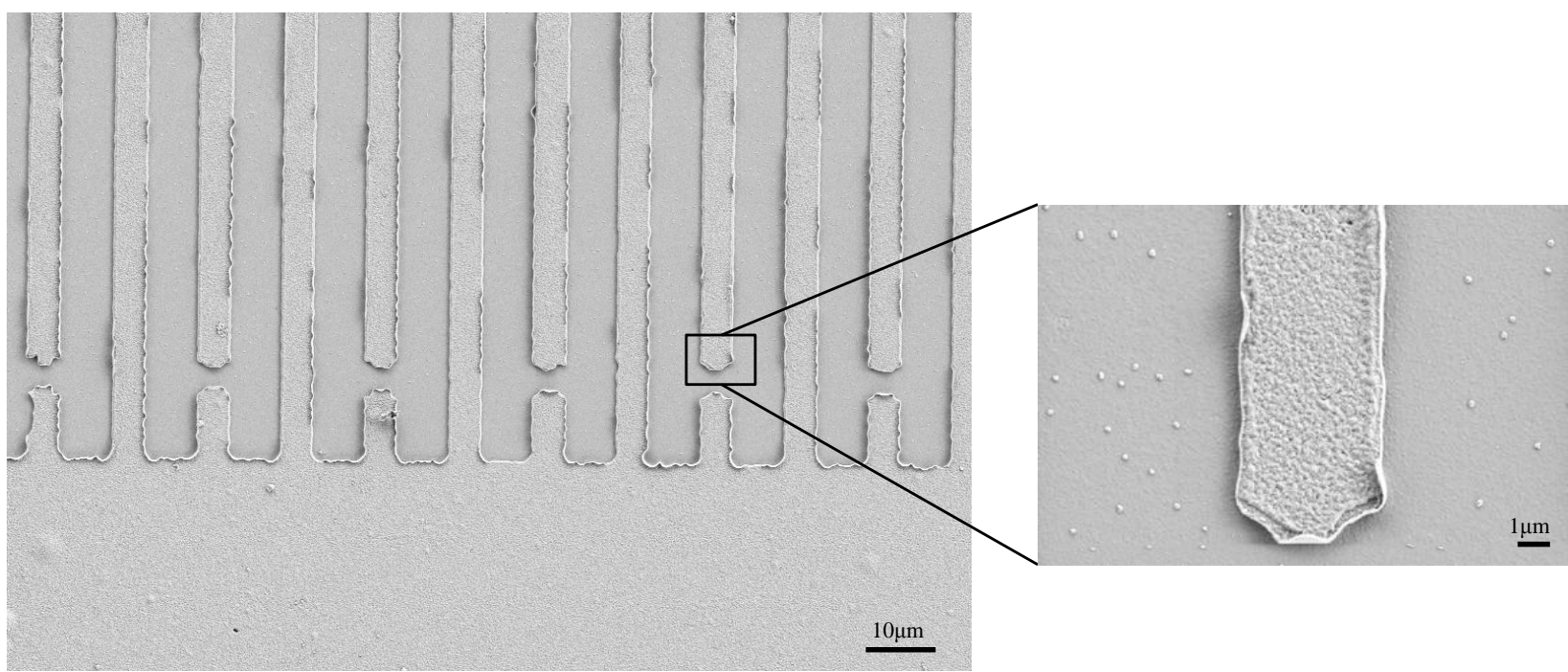

Figure 7: SEM image of $\operatorname{Ir}_{30} \mathrm{Rh}_{70}$ alloy IDTs after $100 \mathrm{~h}$ at $800^{\circ} \mathrm{C}$ in air.

\section{CONCLUSION}

Ir-Rh alloy thin films were deposited from alloy pellets on LGS substrates by one-gun electron beam evaporation method. The control of the film stoichiometry was difficult because of the significant difference in the evaporation rates of $\mathrm{Ir}$ and $\mathrm{Rh}$ elements. Consequently $\mathrm{Ir}-\mathrm{Rh}$ multilayers films constituted of successive $\mathrm{Ir}$ and $\mathrm{Rh}$ nanolayers of same thickness were deposited in order to manage the overall film composition. Different nanostructures were achieved by varying the nanolayers thickness.

The high-temperature behavior in corrosive atmosphere of $\operatorname{Ir}_{10} \mathrm{Rh}_{90}, \mathrm{Ir}_{30} \mathrm{Rh}_{70}$ alloy films and $\mathrm{Ir}_{50} \mathrm{Rh}_{50}$ multilayers films was investigated by 4-days annealing periods at $800^{\circ} \mathrm{C}$ in air. XRD analyses revealed the complete oxidation of all samples with the apparition of $\operatorname{Ir}_{\mathrm{x}} \mathrm{Rh}_{1-\mathrm{x}} \mathrm{O}_{2}$ and $\mathrm{Rh}_{2} \mathrm{O}_{3}$ phases. Electrical resistivity measurements point out that the higher is the initial Ir rate in the film, the lower is the electrical resistivity after annealing. Thus, the resistivity of the $\operatorname{Ir}_{50} \mathrm{Rh}_{50}$ multilayers films was lower than $200 \mu \Omega \cdot \mathrm{cm}$ after the annealing process. TEM analyses show that the multilayer structure was lost during annealing, while an $\mathrm{Rh}_{2} \mathrm{O}_{3}$ overlayer, with a thickness of 
some tens of nanometers, formed at the surface of the film, confirming previous observation made on Ir-Rh bulk alloys. First SAW measurements made on devices based on $\operatorname{Ir}_{10} \mathrm{Rh}_{90}$ alloy IDTs showed that the signal was lost. On the other hand, the SAW measurements made on $\mathrm{Ir}_{30} \mathrm{Rh}_{70}$ alloy IDTs are very promising as a SAW signal is still clearly visible after the 4-days annealing process, while no agglomeration phenomenon can be observed. Complementary experiments are ongoing to investigate the behavior of SAW devices based on $\operatorname{Ir}_{50} \mathrm{Rh}_{50}$ multilayers IDTs.

Various studies will have to be done in order to confirm these first promising results. Longer annealing periods at $800^{\circ} \mathrm{C}$ will be performed in order to determine the time-evolution of the $\mathrm{Rh}_{2} \mathrm{O}_{3}$ overlayer observed on the multilayers films after annealing. In the same way, the behavior of the films at higher temperatures, for which pure $\mathrm{Ir}$ volatilizes in $\mathrm{IrO}_{3}$, will be investigated. Finally, Ir-rich multilayers film will be investigated in order to optimize the IDTs electrical behavior.

Acknowledgement. This work was financially supported by the Lorraine Regional Council. We are also grateful to Dr. Pascal Boulet for fruitful discussions concerning the XRD results. 


\section{References}

[1] J. Hornsteiner, E. Born, G. Fischerauer, and E. Riha, "Surface acoustic wave sensors for high temperature applications," in Proc. Annu. IEEE Int. Freq. Contr. Symp., 1998, pp. 615-620.

[2] J. Bardong, T. Aubert, N. Naumenko, G. Bruckner, S. Salzmann and L. M. Reindl, "Experimental and Theoretical Investigations of Some Useful Langasite Cuts for HighTemperature SAW Applications," IEEE Trans. Ultrason. Ferroelectr. Freq. Control, vol. 60, no. 4, pp. 814-823, Apr. 2013.

[3] T. Aubert, J. Bardong, O. Elmazria, G. Bruckner and B. Assouar, "Iridium interdigital transducers for high-temperature surface acoustic wave applications," IEEE Trans. Ultrason. Ferroelectr. Freq. Control, vol. 59, no. 2, pp. 194-197, Feb. 2012.

[4] M. Seifert, S. B. Menzel, G. K. Rane, M. Hoffmann and T. Gemming, "RuAl thin films on high-temperature piezoelectric substrates," Materials Research Express, vol. 2, art. no. 085001, 2015.

[5] M. Seifert, G. K. Rane, B. Kirbus, S. B. Menzel and T. Gemming, "Surface effects and challenges for application of piezoelectric langasite substrates in surface acoustic wave devices caused by high temperature annealing under high vacuum," Materials, vol. 8, pp. 8868-8876, 2015.

[6] S. L. Firebaugh, K. F. Jensen and M. A. Schmidt, "Investigation of high-temperature degradation of platinum thin films with an in situ resistance measurement apparatus," J. Microelectromech. Syst., vol. 7, no. 1, pp. 128-135, Mar. 1998. 
[7] J. A. Thiele and M. Pereira da Cunha, "Platinum and Palladium High-Temperature Transducers on Langasite," IEEE Trans. Ultrason. Ferroelectr. Freq. Control, vol. 52, no. 4, pp. 545-549, Apr. 2005.

[8] W. C. Maskell, N. M. Sammes and B. C. H. Steele, "Agglomeration of thin platinum films on a zirconia substrate," J. Phys. D: Appl. Phys., vol. 20, pp. 99-104, 1987.

[9] M. Pereira da Cunha, T. Moonlight, R. Lad, G. Bernhardt and D. J. Frankel, "Enabling Very High Temperature Acoustic Wave Devices for Sensor \& Frequency Control Applications," in Proc. IEEE Ultrasonics Symp., 2007, pp. 2107-2110.

[10] T. Aubert, O. Elmazria, B. Assouar, L. Bouvot, M. Hehn, S. Weber, M. Oudich, and D. Geneve, "Behavior of Platinum/Tantalum as interdigital transducers for SAW devices in hightemperature environments," IEEE Trans. Ultrason. Ferroelectr. Freq. Control, vol. 58, no. 3, pp. 603-611, Mar. 2011.

[11] M. Pereira da Cunha, T. Moonlight, R. Lad, D. Frankel and G. Bernhardt, "High Temperature Sensing Technology for Applications Up To $1000^{\circ}$ C,' in Proc. IEEE Sensors Symp., 2008, pp. 752-755.

[12] R. Behanan, S. C. Moulzolf, M. Call, G. Benhard, D. Frankel, R. J. Lad and M. Pereira da Cunha, "Thin Films and Techniques for SAW Sensor Operation Above $1000^{\circ}$ C," in Proc. IEEE Int'l Ultrason. Symp., 2013, pp. 1013-1016.

[13] T. Aubert, J. Bardong, O. Legrani, O. Elmazria M. B. Assouar, G. Bruckner and A. Talbi, "In situ high-temperature characterization of AlN-based surface acoustic waves devices," J. Appl. Phys., vol. 114, art. no. 014505, 2013. 
[14] Z.B. Bao, H. Murakami and Y. Yamabe-Mitarai, "Effects of thermal exposure on Ir-based alloys with and without Pt coating," Corrosion Science, vol. 53, pp. 1224-1229, 2011.

[15] H. Osamura and N. Abe, "Development of New Iridium Alloy for Spark Plug Electrodes," SAE Trans., vol. 108, no. 3, pp. 1063-1074, 1999.

[16] S. Sakharov, A. Zabelin, S. Kondratiev, D. Richter, H. Fritze, D. Roshchupkin, A. Shvetsov and S. Zhgoon, "Optimization of wafer orientation and electrode materials for LGS hightemperature SAW sensors," in Proc. IEEE Ultrason. Symp., 2012, pp. 1525-1528.

[17] S.N. Tripathi, S.R. Bharadwaj, and M.S. Chandrasekharaiah, "The Ir-Rh (Iridium-Rhodium) System”, Joumal of Phase Equilibria, vol. 12, pp. 606-608, 1991.

[18] Jani Hämäläinen, Frans Munnik, Mikko Ritala and Markku Leskeläa, "Study on Atomic Layer Deposition of Amorphous Rhodium Oxide Thin Films," J. Electrochem. Soc., vol. 156, no. 10, pp. 418-423, 2009.

[19] M. A. El Khakani and M. Chaker, Mater, "Highly Conductive and Optically Transparent Polycrystalline Iridium Oxide Thin Films Grown by Reactive Pulsed Laser Deposition," in Proc. Mater. Res. Soc. Symp., vol. 472, pp. 373-378, 1997.

[20] M. Lisker, T. Hur'yeva, Y. Ritterhaus, and E. P. Burte, "Effect of annealing in oxygen atmosphere on morphological and electrical properties of iridium and ruthenium thin films prepared by liquid delivery MOCVD," Surf. Coat. Tech., vol. 201, no. 22-23, pp. 9294-9298, 2007.

[21] C. U. Pinnow, I. Kasko, C. Dehm, B. Jobst, M. Seibt and U. Geyer, "Preparation and properties of dc-sputtered IrO2 and Ir thin films for oxygen barrier applications in advanced memory technology," J. Vac. Sci. Technol. B, vol. 19, no. 5, pp. 1857-1865, 2001. 